\title{
FENOMENOLOGIA E PSICOPATOLOGIA DO ESPAÇO VIVIDO SEGUNDO LUDWIG BINSWANGER: UMA INTRODUÇÃO ${ }^{1}$
}

\author{
Phenomenology and Psychopathology of Living Space according Ludwig Binswanger: an Introduction
}

Fenomenología y Psicopatología del Espacio Vivido según Ludwig Binswanger: una Introducción

JEANine Chamond

\begin{abstract}
Resumo: Este artigo tem como objetivo introduzir a questão do espaço vivido na psicopatologia fenomenológica de Ludwig Binswager, apresentando o conceito de direção de sentido. Este conceito dá conta de uma experiência ontológica da espacialidade na análise da Presença humana. Mostra que a existência se desenvolve em um espaço-tempo orientado, significante e phatico, tensionado entre as dimensões antagônicas do alto e do baixo, da esquerda e da direita, da frente e do atrás, do perto e do longe etc. O privilégio antropológico da altura se impõe ao homem como necessidade de se realizar em sua existência encontrando sua altura própria, proporcionada pela largura de sua experiência dos outros homens e do mundo.
\end{abstract}

Palavras-chave: Fenomenologia; Espaço Vivido; Psicopatologia Fenomenológica.

\begin{abstract}
This article aims to introduce the issue of lived space in phenomenological psychopathology of Ludwig Binswanger, presenting the concept of sense of direction. This concept realizes an ontological experience of spatiality in the analysis of human presence. Shows that the existence unfolds in a space-time oriented, meaningful and phatic, stretched between the dimensions of the opposing top and bottom, left and right, front and back, near and far and so on. Anthropological point of privilege is necessary to man as a need to accomplish in your life finding your own time, provided the width of his experience of others and the world.

Keywords: Phenomenology; Living Space; Phenomenological Psychopathology.

Resumen: Este artículo pretende introducir la cuestión del espacio vivido en la psicopatología fenomenológica de Ludwig Binswanger, presentando el concepto de sentido de dirección. Este concepto da cuenta de una experiencia ontológica de la espacialidad en el análisis de la presencia humana. Muestra que la existencia se desarrolla en un espacio-tiempo orientado, significativo y pático, tensionado entre las dimensiones de la parte superior e inferior, izquierda y derecha, adelante y atrás, en la cerca y de lejos y así. El privilegio antropológico de la altura es necesaria para el hombre realizar su existéncia en una altura propria, proporcionada por la anchura de su experiencia de los demás y del mundo.

Palabras-clave: Fenomenología; Espacio Vivido; Psicopatología Fenomenológica.
\end{abstract}

\section{Introdução}

Nascido em 1881, na Suíça alemã, em uma família de psiquiatras, Ludwig Binswanger dirigiu, a partir de 1911 - em seqüência a seu avô, seu pai e seu tio - a célebre clínica Bellevue em Kreuzlingen, nas margens do lago de Constance. De reputação internacional, esta clínica recebeu toda a elite intelectual européia da época, que precisava de tratamento: incluindo o bailarino Nijinski, o célebre crítico de arte Aby Warbourg; o filósofo Nietzsche, considerado louco, foi recebido por seu tio, entre outros. Um grande número de intelectuais e de artistas, dentre os quais Husserl e Heidegger, foram convidados a visitar a clínica, que está hoje desmembrada, tendo sido objeto de uma especulação imobiliária desenfreada.

Conferência proferida na Universidade de Fortaleza (Unifor), promovida pelo grupo APHETO (Laboratório de Psicopatologia e Psicoterapia Humanista Fenomenológica Crítica), em maio de 2011. Texto original traduzido por Lucas Bloc, Juliana Pita e Virginia Moreira.
Aluno, e em seguida, assistente de Eugen Bleuler (1857-1939), Ludwig Binswanger faz sua tese de medicina com Carl Gustav Jung. É na companhia de Jung, que ele parte para Viena, em 1907, para conhecer Freud. A partir daí, começa a adquirir uma formação analítica e constrói uma sólida amizade com Freud, testemunhada pelas correspondências durante trinta anos, e publicadas por Calmann-Lévy. Freud enviava pacientes para a clínica Bellevue e esperava um dia fazer de Binswanger seu herdeiro espiritual. A formação intelectual de Binswanger é dupla : psiquiátrica e filosófica. Sua formação filosófica faz sentido pela recusa do pensamento objetivante próprio das ciências da natureza, que vê no homem um organismo psico-físico, um sistema de funções orgânicas ligadas aos processos naturais. É esta formação filosófica que também virá a distanciá-lo da psicanálise. Do ponto de vista da filosofia, Binswanger se situa inicialmente na linha de pensamento do fenomenólogo Edmund Husserl e de sua exploração da consciência intencional. Segundo 
Kuhn \& Maldiney (1971), o que liga Binswanger a Husserl pode ser resumido em uma das frases escritas por Husserl no livro de ouro da clínica em Kreuzlingen, quando de sua visita: "O que é realmente visível no fenômeno, não é para ser transformado interpretando-o, é necessário tomá-lo onde ele está, na forma como ele se dá, e descrevêlo verdadeiramente" (p. 13).

Vemos aqui a diferença fundamental entre Fenomenologia e Psicanálise no tratamento do sintoma: o fenomenólogo considera o fenômeno/sintoma no seu aparecimento para descrevê-lo na sua totalidade, a partir da famosa epoché, a suspensão de todo julgamento e de toda tese implícita ou explícita sobre a realidade (não a realidade, mas suas condições de possibilidade). Enquanto a Psicanálise parte do princípio anterior, que há uma verdade escondida atrás do fenômeno/sintoma: a verdade do desejo, do inconsciente.

Mas o pensamento de Husserl não é suficiente a Binswanger para esclarecer a magnitude das modificações psiquiátricas do ser humano. Em 1927, Binswanger descobre Heidegger, através de sua publicação do Ser e Tempo. O Ser-no-mundo heideggeriano lhe permite descrever os mundos constituídos dos doentes mentais. O Dasein é um conceito fundamental em Heidegger: o seraí, o existente, ou ainda, a Presença. Binswanger funda, então, a Daseinsanalyse - a análise do Dasein - ou ainda a "análise existencial", que tem como objetivo a análise da presença humana.

Próximo ao fim de sua vida, Binswanger conhece uma espécie de bifurcação intelectual que chamamos de "o retorno a Husserl", e que pode ser constatada em suas duas últimas obras: Manie et Mélancolie (1960) e Délire (1965). Neste momento, Binswanger busca uma fenomenologia não mais da consciência, mas da subjetividade, que ele encontra no Ego, na egologia transcendental do Husserl tardio.

Binswanger é o autor de um número considerável de artigos e de livros, nem todos traduzidos para o francês, como por exemplo, sua obra mestra: a monumental Grundformen und Erkenntnis menschlichen Daseins ("Formas fundamentais e conhecimento da presença humana"), publicada em 1942. Sua obra é, às vezes, difícil, densa, indicando uma cultura enciclopédica, por vezes, pesada: uma das razões, talvez, pela qual ela não é muito difundida. A outra razão é que ela foi eclipsada pela psicanálise. Binswanger morreu em 1966, desconhecido na época.

Para Binswanger, o "louco" deve ser considerado antes de tudo a partir do ser-com (Mit-Mensch). Este fundo comum é nosso "ser-no-mundo", cujas estruturas foram analisadas e elaboradas por Heidegger. Todas as formas de transtorno - ou de doença - mental são, assim compreendidas como uma modificação da estrutura do serno-mundo, da presença (Dasein) nas suas relações com ele-mesmo, com o outro e com o mundo.

\section{Binswanger e Freud}

Binswanger é um jovem psiquiatra quando encontra Freud, que tinha cinquenta anos de idade na época, e estava no topo de sua glória. Leitor e admirador de sua obra, Binswanger hesita em se fazer discípulo de Freud, e finalmente decide continuar seu próprio caminho, mantendo a psicanálise próxima e distante: a Daseinsanalyse. Como assinalam Kuhn \& Maldiney (1971), a Daseinsanalyse não é a repetição da psicanálise em outra linguagem. Da psicanálise, Binswanger guarda o princípio da cura, do desdobramento da historicidade no seio de uma relação dual. Mas ele critica a noção de transferência (Ubertragung), substituindo-a pela de Tragung, literalmente um tipo de "carregar psiquicamente" ("le portage", em francês). Binswanger demanda ao terapeuta uma implicação bem mais importante que a clássica neutralidade bem assegurada do psicanalista, se colocando em total oposição à atitude lacaniana de não intervenção. Para a Daseinsanalyse, não há uma verdade escondida do inconsciente por detrás do sintoma, que só o psicanalista poderia descobrir, também o paciente é um intérprete de seu sofrimento.

Binswanger rejeita, por outro lado, definitivamente a concepção freudiana de homem, o Homo Natura, edificado sobre o modelo das ciências naturais, e fundado sobre o substrato da pulsão. A psicanálise é, para ele, um materialismo: o superior, o espírito, a capacidade de criação decorrente da pulsão, é também decorrente do orgânico. A questão do conflito entre Daseinsanalyse e a psicanálise é a gênese do espiritual. Para Freud, o espírito vem do corpo. Para Binswanger o espírito vem do próprio espírito. Sem negar o "sexual" freudiano, Binswanger o inclui em um conjunto mais vasto: o da existência. Para os psicanalistas, Binswanger não leva em conta o inconsciente.

Binswanger define a análise existencial como uma ciência empírica, preocupada com uma abordagem antropológica da essência individual do ser humano. Em oposição às Ciências da Natureza que vêem o homem como um sistema de funções orgânicas, ele visa explorar a existência subjetiva do homem entendida na sua totalidade, como ser presente no mundo, responsável de sua própria existência. Seu método é uma análise da presença nas suas estruturas espaciais e temporais.

\section{Bisnwanger e Heidegger}

A analítica existencial de Heidegger visa desvendar as estruturas ontológicas da existência. Por Ontológico entende-se o que se refere ao Ser em geral, por oposição ao Ôntico, que se refere aos seres particulares. Existencial aqui tem o sentido de "constitutivo do existir humano", de "próprio do existir humano". As estruturas ontológicas ou os existenciais pertencem à essência do ser homem: não podemos não os ter, eles não podem desaparecer, 
inclusive nas formas mais graves de psicoses, segundo um contra senso comum em fenomenologia psiquiátrica. Dito de outra forma, o psicótico, mesmo o mais atingido pela psicose, não pode não estar no tempo, no espaço, na corporeidade, na relação com os outros; mas a patologia pode alterar, distorcer, bloquear suas coordenadas existenciais.

Os existenciais, segundo Heidegger são, primeiramente, o tempo e o espaço, mas também: O ser-no-mundo, ou o ser dentro do mundo, que significa que o ser está em uma relação originária no mundo; o ser-com-outro, com um outro ou com os outros. O mundo já é sempre um mundo comum, ou seja, um Mitsein, literalmente um ser-com. Heidegger afirma : "O Dasein é Mitsein” (ser-com).

Outros existenciais são a disposição, o humor ou a tonalidade afetiva, a Stimmung, o fato de ser afetado - cada experiência de mundo se dá, de início, na sua coloração afetiva - e, o compreender, a fala e a preocupação. Para resumir, poderíamos dizer que para Heidegger, o ser é primordialmente temporal, espacial, ser-no-mundo, ser com o outro, afetado, compreendendo.

\section{As Direções do Sentido}

As direções de sentido, em alemão Die Bedeutungrichtung são, literalmente, as direções (Richtung) de significações (Bedeutung). Para Binswanger, a existência se estende segundo uma unidade fundamental, um estilo de vida, que engloba ao mesmo tempo as direções espaciais que tomamos e a significação que damos às coisas. É por isso que a polissemia da palavra sentido em francês me parece particularmente bem-vinda para explicitar a noção de direção de sentido de Binswanger, já que ela compreende o sentido como significação, o sentido como direção e o sentido como ação do sentir e sensibilidade.

O espaço vivido na Daseinanalyse não é o espaço matemático euclidiano, é o existente em seus atos cotidianos que abre, cria o espaço. O espaço no qual ele se implica, se desenvolve e se projeta.

Segundo Jacques Schotte (1986), o conceito de direção de sentidos está inspirada em Binswanger por Karl Löwith, autor de uma tese orientada por Heidegger. Löwith se pergunta porque um termo como "altura" pode se aplicar a diferentes registros tais como o mundo físico, moral, sensorial, estético, espiritual etc. Não se trata de falar de uma metáfora, mas de uma estrutura ontológica da existência humana: a altura. Para compreender isso, proponho seguir Binswanger na sua antropologia da queda. Dito de outra forma, para um homem: o que é cair?

Binswanger estuda a questão no seu artigo "Sonho e existência”, de 1930, publicado no livro Introduction a l'Analyse Existentielle. ${ }^{2}$ Quando, no decorrer de uma experiência de decepção profunda e brutal, nós dizemos que

\footnotetext{
2 Publicado, na versão francesa em 1947, 1955 e 1971, pelas Éditions de Minuit.
}

caímos das nuvens, que fomos atingidos por um raio, nas palavras de Binswanger (1954/1971), "realmente nós caímos; mas não é uma queda puramente física” (p. 199). ${ }^{3}$

A imagem da queda expressa uma possibilidade concreta da espacialidade vivida, do corpo habitando o espaço: ela é uma estrutura antropológica do mundo, uma forma de habitá-lo, aquela da perda do apoio e da harmonia, da ruptura em uma corporeidade tranqüila. Mas além do corpo que cai realmente, a imagem da queda traduz a essência mesma da perda do escoramento e do vivido de terror que lhe é consubstancial. A queda descreve uma possibilidade fundamental de ser no mundo: a perda do equilíbrio, o colapso, o terror.

A imagem da queda é um nó originário abrindo um campo de significações potenciais múltiplas. Ela é uma das grandes orientações da existência, na qual coincidem uma direção especial (para baixo) e um sentido aberto, não temático, da ordem da perda do escoramento do Dasein: ela é simultaneamente uma forma, um sentido e um sentimento.

A queda pode tomar significados particulares, por exemplo, espaciais, espirituais, psíquicos, etc., porque ela se esconde no buraco que lhe é originariamente comum. Falamos, por exemplo, de queda do cavalo, da moral, do dólar, do governo, da queda d'água porque está sempre em questão algo como a perda do equilíbrio, o colapso, a depressão, etc. Em francês se diz que o homem pode cair de sono, cair de amor, cair doente ou cair morto: sempre, ele cai.

Vemos, então, um primeiro esboço da direção de sentido como uma estrutura ontológica da existência, na encruzilhada da linguagem, do corpo vivido se desenvolvendo no espaço segundo as direções determinadas, do sentido e da timia (do humor) inerente ao Dasein.

\section{As Direções do Sentido: uma Dupla de Opostos}

A queda é uma estrutura ontológica do Dasein e de seu poder de se dirigir no espaço. Mas ela só se torna verdadeiramente direção de sentido porque ela é acoplada ao seu oposto, a escalada, a ascensão na altura, o salto, etc.

A direção de sentido é uma estrutura unitária puxada, esticada, entre duas polaridades contrárias. O Dasein tanto pode cair, como pode, em um mesmo movimento, mas oposto, subir, saltar, fazer a experiência da altura e da ascensão: eu caio do céu na decepção brutal, eu pulo ou salto no ar num momento de alegria extrema. Dito de outra forma, a orientação do corpo no espaço, o alto e o baixo, direita e a esquerda, frente e trás, etc., não são simples caracterizações intra-mudanas do Dasein cor-

\footnotetext{
Uma versão desse texto encontra-se traduzida e publicada na revista Natureza Humana, volume 4, Nr.2, 2002, disponível online em: http://pepsic.bvsalud.org/scielo.php?pid=S151724302002000200007\&script=sci_arttext (Nota do Editor).
} 
poral. O alto e o baixo são uma determinação essencial em relação ao mundo, que são a queda e a ascensão. Da mesma forma, frente e atrás.

Binswanger determina um certo número de direções de sentido, em uma lista aberta. Estas direções de sentido são formuladas sempre como uma dupla de opostos, que expressam a espacialidade da existência em situação: a queda e a ascensão, a amplitude e a estreiteza, a esquerda e a direita ${ }^{4}$, o próximo e o longe, o na frente e o atrás, etc. Maldiney (1996) os chama "os tensores da existência”.

Cada termo só tem sentido no seio da dualidade que ele forma com seu contrário e que constituem as diástoles e sístoles da existência. Convém acrescentar às direções de sentido outras polaridades com os correlatos fenomenológicos que colorem a presença, tais como o claro e a sombra, o leve e o pesado, o largo e o estreito, o congelado e a queimadura, o pesado e o aéreo... Podemos os reencontrar nas situações da vida onde vivemos uma atmosfera pesada, um rir congelado, um momento sombrio da existência, os encontros que ampliam nosso horizonte, etc. É importante observar isto nos discursos dos pacientes.

Em fenomenologia, o espaço sempre é espaço tímico, ou seja, um espaço afetado por uma coloração afetiva fundamental. A tonalidade climática especifica uma forma de "presença à..."; ou seja, um modo de comunicação determinado com as coisas, num mundo que não está simplesmente diante de nós, mas que atravessa o pathos inerente à situação.

Há um privilégio antropológico da altura; a direção de sentido do alto e do baixo é privilegiada em relação às outras, por conta da posição de pé do homem, privilégio que pode estar relacionado ao colocar-se em pé do homem. Expansão e limitação, altura e largura, pertencem à natureza do homem, ao caminhar e ao estar em pé. A verticalidade continua a ser a direção significativa do esforço e da vontade, posto que o homem deve apreendê-la.

\section{Proporção e Desproporção Antropológicas}

O equilíbrio entre as direções de sentido constitui aquilo que Binswanger chama de a proporção antropológica. A proporção justa, por exemplo, entre o baixo e o alto, permite ao homem encontrar sua medida justa, de ser sua própria possibilidade na sua história e de encontrar sua forma pessoal de realização.

Para Binswanger, todo homem deve se realizar na sua existência, seja qual for o sentido que esta realização possa tomar. Todos nós temos uma aspiração legítima a "abusar na altura”: a realização de si é a coisa mais alta

\footnotetext{
4 As respostas simétricas ao Rorschach. Na esquizofrenia, a simetria pode ser a última bóia salva-vidas à qual a presença se agarra e graças ela tenta não escurecer no caos. Ela é o último princípio de ordem do mundo, e o último esforço, como o diz o esquizofrênico Jürg Zund, de se conservar a si-mesmo. Mas ela significa uma geometrização do mundo, portanto, um afastamento e um aprofundamento da vida, uma racionalização.
}

que o homem possa alcançar. Mas esta realização de si depende da concordância entre duas direções de sentido: a altura e horizontalidade.

De fato, a horizontalidade, o caminhar na extensão, desdobra-se entre os dois pólos opostos da largura e da limitação. Ela representa a vida prática, a experiência cotidiana, a discursividade, a abertura aos outros. Mover-se na horizontalidade é realizar-se na vida prática, avançar no amplo, ampliar seus horizontes e adquirir uma visão do conjunto sobre o mundo para compreendê-lo.

A aspiração à altura, a subida na verticalidade passa pelo aprofundamento problemático de si, a pesquisa espiritual, a visão mais larga e mais alta das coisas. A altura corresponde antropologicamente ao desejo de triunfar sobre o peso terrestre, que permite verdadeiramente se apropriar da experiência.

A justa proporção antropológica se define pela proporção da verticalidade e da horizontalidade, pelo equilíbrio entre a ascensão e o caminhar, entre a vontade de crescer e de pegar altura e da experiência prática do alargamento da vida, ou ainda entre a visão mais alta e mais larga sobre o mundo. Dito de outra maneira, a saúde depende da justa proporção antropológica entre a aspiração para chegar ao alto e a compreensão do mundo (na horizontalidade).

O paradigma da realização de si, para Binswanger, pode encontrar-se na Arte. Ele vê um exemplo da realização de si no dramaturgo norueguês Ibsen. Em 1949, ele o consagrou em um belo livro chamado "Henrik Ibsen e o problema da autorealização de si na arte" (publicado pela Universidade De Boeck) com um posfácio de Henri Maldiney. A biografia de Ibsen e também sua peça de teatro "Solness, o construtor" ilustram a teoria de Binswanger da justa proporção antropológica.

\section{Desproporção e Formas da Presença Faltantes no Mundo}

Quando existem desproporções antropológicas entre as dimensões espaciais da presença, o ser homem não pode se realizar autenticamente. A desproporção resulta da acentuação e da absolutização de uma direção, que se emancipa da dupla polaridade para o vir exclusivo. Ela é, então, uma flexão excessiva da existência comum. Tatossian (2006) define a psicose como o desequilíbrio que atualiza e impulsiona ao extremo uma das potencialidades humanas em detrimento de outras. A desproporção pode resultar do desequilíbrio entre uma aspiração elevada demais e uma base demasiadamente limitada da experiência, como um edifício que, sem ter alicerces sólidos, cai.

Para Binswanger (1956) existem três formas de desproporção antropológica: a presunção, a distorção e o maneirismo. Aqui discutimos apenas a presunção. Esta ocorre quando a presença ou o Dasein visa alto demais em 
relação às suas possibilidades, fica perdido nas alturas, longe do mundo comum, do Mitsein. O excesso de altura torna-se um bloqueio da existência humana.

$\mathrm{Na}$ maior parte de seus casos de esquizofrenia, Binswanger observa a fase de um ideal presunçoso. A presunção não é um sintoma apenas da esquizofrenia. Mas ela tem uma afinidade com a esquizofrenia e precede a rigidez e a dissociação esquizofrênica; ela assinala o bloqueio da presença.

Para o maníaco existe uma desproporção pelo desequilíbrio entre altura e horizontalidade. O acesso maníaco se caracteriza pela perda da dimensão da horizontalidade, da alteração do tempo vivido, do alargamento desordenado do espaço. Em Sobre a fuga de idéias, editado em 1933, Binswanger descreve como a fuga ordenada das idéias determina um modo saltitante da existência, e a fuga desordenada das idéias produz o turbilhão. O maníaco conhece o vôo imaginário de ser-levado-aos-ares sobre as asas do simples desejo, por suas quimeras. Antropologicamente, esse é o sonho de voar que sempre assombrou o imaginário humano, como no mito de Ícaro.

Binswanger não evoca explicitamente, na minha opinião, a noção de direção de sentido do afundamento melancólico. Mas para dar conta da destruição melancólica, pode-se citar as respostas de seu paciente melancólico. No livro Mélancolie et Manie, o paciente melancólico Reto Ross diz que ele não se sente agarrado em nenhuma parte, que se sente afundando na profundeza; as decepções passadas ressurgem e seu peso o enterra cada vez mais no solo, ele se sente submergido nele mesmo. Vemos aí a dimensão da queda e do afundamento nas profundezas, bem como a perda de qualquer dimensão de altura.

Para Binswanger, a presunção se produz quando o Dasein se exila do Nós, fora do âmbito do amor e da amizade, longe de toda plenitude possível no "ser-transbordante-do-mundo", longe da eternidade do amor, o que seria a utopia de Binswanger.

\section{Referências}

Binswanger, L. (1971). Le Reve et l'existence. Em L. Binswanger, Introduction à l' Analyse Existencielle (pp. 199-226. Paris: Éditions de Minuit. (Originalmente publicado em 1930).

Binswanger, L. (2002). Trois formes manquées de la présence humaine: la présomtion, la distorsion, le maniérisme. Paris: Le Cercle Herméneutique. (Originalmente publicado em 1956).

Kuhn, R., \& Maldiney, H. (1971). Préface. Em L. Binswanger, Introduction à l'Analyse Existencielle (pp. 7-24). Paris: Les Éditions de Minuit.

Maldiney, H. (1996). Ludwig Binswanger et le problème de l'autoréalisation de soi dans l'art. Postface. Em L. Binswanger, Henrick Ibsen et le problème de l'autoréalisation de soi dans l'art. Bruxelles: DeBoeck Université.

Schotte, J. (1986). Le dialogue Freud-Binswanger et la constitution actuelle d'une psychiatrie scientifique. Em Phénoménologie, Psychiatrie, Psychanalyse (pp. 55-78). Paris: Echo-Centurion.

Tatossian, A. (2006). Fenomenologia das Psicoses. São Paulo: Escuta. (Originalmente publicado em 1997).

Jeanine Chamond - Professora da Universidade Paul Valéry (Montpellier III), na França. É co-presidente da École Française de Daseinsanalyse. Tem Mestrado e Doutorado na área de psicopatologia clínica. É pesquisadora do Laboratoire Dynamique des Capacités Humaines et des Conduites de Santé (Epsylon), da Universidade de Montpellier. Endereço Institucional: 4, Bd Henri IV, 3400 (Montpellier). Email: jeanine.chamond@univ.montp3.fr

Recebido em 15.06.2011

Aceito em 19.08.2011 